\title{
ARTIGOS
}

\section{DESIGN E IMPRESSÃO 3D NA PANDEMIA: UMA ANÁLISE DE POSSIBILIDADES A PARTIR DO MODELO TEÓRICO DFSS}

\section{DESIGN AND 3D PRINTING IN PANDEMICS: AN ANALYSIS OF POSSIBILITIES BASED ON THE DFSS THEORETICAL MODEL}

CLÁUDIO PEREIRA DE SAMPAIO, Dr. | UEL

SONIA MARIA FABRIS LUIZ, Dra. | UEL

\begin{abstract}
RESUMO
Este artigo apresenta um estudo crítico do desenvolvimento de soluções de aplicação da tecnologia de impressão 3D para a saúde pública em um hospital universitário da rede pública brasileira, tendo como contexto a pandemia de covid-19 que atingiu o Brasil e o mundo no ano de 2019. Apresenta como base teórica e metodológica norteadora o design e seus níveis de intervenção, bem como a abordagem de sistemas e problemas complexos. Os autores descrevem três casos de aplicação distintos em nível local, sendo dois em nível de produto e um em nível de sistema, e os analisam de forma qualitativa utilizando um framework de análise em nível de produto, processo e paradigma, desenvolvido por Corsini e Moultrie (2019). Como resultado, são apresentados e discutidos aspectos críticos de cada caso, bem como oportunidades de melhoria e sugestões para novos estudos, e enfatiza-se a criação de um núcleo de fabricação de digital em um hospital público como alternativa sistêmica para os problemas identificados no início do estudo.
\end{abstract}

PALAVRAS-CHAVE: Saúde pública; impressão 3D; design para a sustentabilidade.

\begin{abstract}
This article presents a critical study of the development of solutions for the application of 3D printing technology for public health in a university hospital in the Brazilian public network, in the context of a pandemic of covid-19 that hit Brazil and the world in 2019. It presents as a theoretical and methodological basis the design and its levels of intervention. The authors describe three different application cases at the local level, being two at product level and one at system level and analyze qualitatively using an analysis framework at the product, process and paradigm level, developed by Corsini and Moultrie (2019). As a result, critical aspects of each case are presented and discussed, as well as opportunities for improvement and suggestions for further studies, and it is emphasized the implementation of a digital fabrication center in a public hospital as a systemic alternative for dealing with the problems identified in the research.
\end{abstract}

KEYWORDS: Public healthcare; 3d printing; design for sustainability. 


\section{CONTEXTO GERAL: A PANDEMIA DE CO- VID-19 E A EMERGÊNCIA DA FABRICAÇÃO DIGITAL NA SAÚDE PÚBLICA}

A atual pandemia de Covid-19 causada pelo novo coronavírus (Sars-Cov-2) desenvolveu não só uma crise global de saúde pública, mas também de impacto crescente nas cadeias produtivas, de suprimentos e de serviços na área da saúde (CRAVEN, 2020). O surto de Covid-19 tem representado um desafio para hospitais públicos em todo o mundo e para os brasileiros, entre eles o Hospital Universitário de Londrina (HU/UEL), no que se refere à proteção dos profissionais de saúde que atuam no atendimento de pacientes infectados; na escassez de itens essenciais aos procedimentos clínicos (ventiladores, sondas de aspiração, filtros bacterianos, entre outros) e de diagnóstico (Ex. swab - cotonete nasal) (CORSINI, 2020). A necessidade de se prover produtos adequados, tanto para os profissionais de saúde (ex. Equipamentos de Proteção Individual ou EPIs) quanto para os pacientes, têm esbarrado em uma série de dificuldades que vão desde a dificuldade de importação de equipamentos; a compra de insumos por fornecedores nacionais, cuja oferta é muitas vezes insuficiente para atender a demanda com consequente aumento geral dos custos destes materiais; até a falta de adequação e flexibilidade das soluções ao contexto específico do HU. Tomandose como exemplo o caso dos EPIs, atualmente o HU/UEL conta com centenas de profissionais que necessitam deste tipo de equipamento, incluindo máscaras, óculos, face shields, aventais e gorros descartáveis, entre outros.

A dificuldade de compra dos EPIs durante a pandemia tem, por outro lado, estimulado o protagonismo de indivíduos e empresas que possuem equipamentos de fabricação digital, e sobretudo de impressão 3D, os quais têm se organizado de forma espontânea para ajudar a produzir equipamentos em diversas cidades do mundo e também do Brasil, incluindo Londrina. A fabricação digital abrange diversas tecnologias de manufatura para a produção de quantidades limitadas de produtos, e permite que a produção possa ser feita localmente a partir de modelos digitais $2 \mathrm{~d}$ ou $3 \mathrm{~d}$, utilizando-se tanto tecnologias aditivas (como a impressão 3D), quanto subtrativas como a usinagem de controle numérico computadorizado (CNC) e o corte laser. Tais modelos podem ser alterados, testados e aprimorados rapidamente, o que facilita a melhoria, tanto dos produtos quanto do próprio processo de produção (CRAVEN, 2020). Em países em desenvolvimento diversos projetos de uso de fabricação digital para a área da saúde pública têm sido desenvolvidos; como exemplo, a organização britânica Field Ready desenvolveu, em parceria com a Universidade de Edimburgo e pesquisadores nepaleses, um catálogo de soluções imprimíveis em $3 \mathrm{~d}$ para atender aos nepaleses vitimados por um grande terremoto ocorrido anos antes, e que sofriam com a falta de equipamentos nos hospitais locais. Como resultado, diversos equipamentos médicos foram produzidos localmente (CORSINI; MOULTRIE, 2019).

A fabricação digital tem sido um importante recurso alternativo de produção de EPIs para os hospitais públicos brasileiros, como atestam várias iniciativas colaborativas que emergiram pelo país desde o início do ano de 2020. Entre elas o Projeto Higia, Nutes e SOS3D, e diversos grupos formados por proprietários de impressoras $3 \mathrm{D}$, organizados de forma espontânea via redes sociais como Facebook e Whatsapp em várias cidades brasileiras. Este tipo de ação é favorecido e potencializado pela oferta de plataformas online abertas, que disponibilizam soluções em regime de acesso aberto (open source) de produtos desenvolvidos colaborativamente, como Prusa Printers e Delve, entre outras. A rápida adoção de tais soluções no período de pandemia indica sua viabilidade técnica e econômica para o uso em hospitais públicos, nesta emergência (CHOONG, et al, 2020).

\section{CONTEXTO ESPECÍFICO: O HOSPITAL UNI- VERSITÁRIO DE LONDRINA (HU/UEL)}

O Hospital Universitário de Londrina (HU) é um Órgão Suplementar da Universidade Estadual de Londrina (UEL), e está vinculado administrativamente à Reitoria da Universidade e academicamente ao Centro de Ciências da Saúde, sendo reconhecido pelo Ministério da Educação e Ministério da Saúde, nos termos da Portaria Interministerial MEC/MS № 1.213 de 30.05.2014. Quanto à relevância do HU/UEL, é o segundo maior hospital público do Paraná, sendo considerado um estratégico e tradicional centro de referência em média e alta complexidade, 100\% SUS (Sistema Único de Saúde). Conta com 307 leitos, todos à disposição do SUS, e atende pacientes de cerca de 250 municípios do Paraná e de mais de 100 cidades de outros estados, principalmente São Paulo, Mato Grosso, Mato Grosso do Sul e Rondônia. Sua abrangência regional atual é de cerca de 3.841 .000 pessoas. Sendo um hospital-escola, o HU/UEL tem também a função de espaço de aprendizagem para a prática dos futuros profissionais de saúde (Medicina, Fisioterapia, Enfermagem, FarmáciaBioquímica e Odontologia), além de ser um campo de pesquisa Stricto sensu e Lato sensu para estas e outras áreas. O hospital conta com Habilitações em Assistência de Alta Complexidade na área de queimados; cardiovascular; traumato-ortopedia; neurologia/neurocirurgia; referência 
hospitalar em gestação de alto risco, dentre outros. No ano de 2019 o HU realizou cerca de 151.368 consultas médicas e não médicas e casos cirúrgicos. Desde o início da pandemia em 2020, o HU/UEL é o hospital de referência para Covid-19 da 17a Regional de Saúde do Governo do Estado do Paraná, que abrange 21 municípios, com cerca de um milhão de habitantes. Atualmente conta com 120 leitos exclusivos (UTIs e enfermarias) para casos suspeitos/ confirmados de moderada a grave complexidade. Com isso o hospital deu salto de 307 para 451 leitos disponibilizados, assim como atendimento de referência na rede de urgência e emergência, incidiu para uma população estimada em 2 milhões de habitantes de 96 municípios da macrorregião Norte do Estado. Este fato consolida o HU/ UEL como o segundo maior hospital público do Paraná, 100\% SUS1. Tais números demonstram a significativa relevância do HU/UEL para a população não apenas de Londrina, mas de várias cidades adjacentes e apresenta excelente oportunidade de aplicação da fabricação digital em diversas frentes, incluindo infectologia, pediatria, neurologia, pneumologia, cirurgia e ortopedia.

\section{ONTOLOGIA (NATUREZA) DO PROBLEMA: COMPLEXIDADE E WICKED PROBLEMS}

A delimitação ontológica representa uma etapa relevante neste estudo, pois possibilita caracterizar a natureza do problema (o que é) em termos do seu nível de ordem interna, ou seja, de complexidade. Esta delimitação ajuda a definir, em grande parte, a atitude científica (epistemologia) e o modo (metodologia) de como o problema será abordado posteriormente. Neste sentido, e a partir das categorizações propostas por Snowden (2005) - problemas simples, complicados, complexos e caóticos - propomos categorizar o problema da aplicação da impressão 3D na saúde pública, no contexto da pandemia de covid-19 como um problema do tipo complexo, e até mesmo com alguns elementos de caos no que se refere ao surgimento e rápida expansão da pandemia. Tal classificação se justifica pelo fato de que este problema abrange uma diversidade de aspectos (sociais, econômicos, tecnológicos, políticos) que se influenciam de forma contínua e em diferentes escalas (local, nacional, mundial), e envolvem uma variedade significativa de atores (profissionais de saúde, pacientes, administradores, fabricantes, pesquisadores, entre outros). Estas características, somadas à dificuldade de definição e delimitação clara do problema, permitem situar estes problemas como wicked problems, ou seja, problemas que mudam com o tempo, e para os quais pode haver uma resposta mais adequada, mas nunca uma solução permanente (RITTEL, WEBER, 1973).

\section{EPISTEMOLOGIA DO PROBLEMA: PENSA- MENTO DE SISTEMAS, COMPLEXIDADE, DE- SIGN PARA A SUSTENTABILIDADE, DESIGN DE SISTEMAS, DESIGN THINKING}

Problemas do tipo complexo exigem uma atitude de intervenção que se baseia, conforme Snowden (2005), em três ações principais: sondar (probe), extrair significado (sense) e responder (respond), em ciclos contínuos de aprendizado cada vez mais aprofundado sobre o problema. Esta abordagem decorre de um campo do conhecimento denominado Pensamento (ou Ciência) de Sistemas (Systems Thinking, Systems Science), e especialmente de uma corrente teórica chamada Ciência da Complexidade (Complexity Science).

\subsection{Pensamento de Sistemas (Systems Thinking)}

O Pensamento de Sistemas é uma área de estudos de natureza interdisciplinar que busca a compreensão de fenômenos de natureza complexa, incluindo interações entre o ser humano, suas atividades e tecnologia (sistema sociotécnico) e com o meio ambiente, em nível de sistemas. Compreende-se um sistema como "um todo integrado do qual as propriedades essenciais emergem das relações entre as partes que o compõem" (ISON, 2010), e também como "um todo, uma entidade que um observador pode cognitivamente dissociar de um contexto", e "exibe uma certa forma de organização que determina seu caráter individual" (VANDENBROECK, 2015). Nos problemas complexos o aprendizado só pode ser obtido de forma retrospectiva, ou seja, observando o fenômeno depois que ele ocorreu, a fim de retirar insights que possam alimentar novas intervenções caso outro fenômeno similar ocorra. Tal processo é bastante semelhante ao utilizado no design thinking, no qual a produção e implementação rápida de soluções por meio de artefatos resulta em ciclos contínuos de aprendizado. Neste artigo, o pensamento de sistemas fornece base conceitual para os níveis de análise do processo e paradigma, bem como para a solução 3 (núcleo de fabricação digital Fab.i HU), que serão apresentados e discutidos mais adiante.

4.2 Design: solução de problemas, exploração de oportunidades, criação de valor (inovação), interdisciplinaridade

O pensamento por meio do design, também chamado de Design Thinking, é uma forma específica de pensar sobre a solução de problemas amplos e complexos, centrada em empatia, criatividade e experimentação, como também de um método não-linear, iterativo, essencialmente exploratório e sistêmico de resolver estes problemas. $\mathrm{O}$ design thinking oferece uma nova forma de fazer algo, de 
adequá-lo a um sistema de negócios já existente ou novo, e de gerar valor para um novo produto, serviço ou processo. Apresenta natureza humanista, intuitiva, que leva em consideração tanto o aspecto emocional quanto de funcionalidade do usuário (BROWN, 2010). A noção de valor deve incluir, além do usuário e do negócio, também benefícios para a sociedade como um todo e para os ecossistemas naturais. Neste sentido, o Design para a Sustentabilidade consiste em uma abordagem ampliada do Design que busque contemplar de forma equilibrada as principais dimensões de sustentabilidade (ambiental, social e econômica), seja no redesign de produtos existentes, no projeto de novos produtos e serviços em substituição aos atuais, no projeto de sistemas produto-serviço intrinsecamente sustentáveis, e até mesmo no desenvolvimento de novos cenários de estilos de vida sustentáveis (MANZINI; VEZZOLI, 2002). A fim de ampliar este potencial de sustentabilidade, é relevante também para este estudo a abordagem do Design de Sistemas (Systems Design), que tem por objetivo a criação de sistemas sustentáveis, voltados ao atendimento das necessidades humanas (VEZZOLI, 2010) no contexto de problemas complexos (wicked problems) de sustentabilidade. A questão dos produtos, serviços e sistemas para a saúde pública representa um problema deste tipo, que pode ser abordada por meio de frameworks teóricos próprios (DA COSTA JUNIOR; DIEHL; SNELDERS, 2019).

\section{A TECNOLOGIA: FABRICAÇÃO DIGITAL E A IMPRESSÃO 3D}

Conforme Gershenfeld (2012) a fabricação digital refere-se aos processos que utilizam ferramentas controladas por computador, cuja origem pode remeter ao primeiro processo de usinagem controlada numericamente, desenvolvido em 1952 por pesquisadores do Massachusetts Institute of Technology (MIT). Estes processos incluem a impressão 3D em suas várias formas, usinagem controlada por computador (CNC), corte laser e outros. Segundo Gershelfeld, a parte digital refere-se ao controle computacional, enquanto a parte material em si é, de fato, analógica. Já existem iniciativas de pesquisa, no entanto, que buscam tornar digital também a parte material, o que deverá representar o futuro destas tecnologias nos próximos anos. Destaca-se aqui a impressão 3D, principal processo de produção de objetos em pequena escala, e que pode ser classificado em três categorias (VOLPATO, 2007): Com base em líquidos (ex. Estereolitografia), com base em sólidos (ex. Deposição por Material Fundido ou FDM), e com base em pó (ex. Sinterização Seletiva a Laser).

\section{CLASSIFICAÇÃO DE ATIVIDADES: MODE- LO TEÓRICO DFSS FRAMEWORK}

O instrumento Design for Social Sustainability Framework (DfSS) foi desenvolvido por Corsini e Moultrie (2019) para apoiar o desenvolvimento de projetos humanitários e de desenvolvimento que utilizam a fabricação digital como tecnologia principal, a fim de aprimorar a tomada de decisão no início do processo e avaliar a sustentabilidade dos produtos ao final. O DfSS é composto por três níveis de avaliação (produto, processo e paradigma), cada um abrangendo aspectos específicos de sustentabilidade (Figura 1). Devido à efetividade e facilidade de uso já exemplificada por Corsini e Moultrie (2019) em outros casos de aplicação, este framework será utilizado como ferramenta de avaliação também neste artigo, no qual serão analisados três casos de aplicação da fabricação digital para a saúde pública.

\begin{tabular}{|c|c|c|c|c|}
\hline Paradigma & \multicolumn{2}{|c|}{$\begin{array}{l}\text { 14) Avanço } \\
\text { Cria postos de trabalho no país? Aproveita as habilidades } \\
\text { existentes? Desenvolve novas habilidades? }\end{array}$} & \multicolumn{2}{|c|}{$\begin{array}{l}\text { 15) Empoderamento } \\
\text { Reduz a dependência? Empodera pessoas } \\
\text { para desenvolver suas próprias soluções? }\end{array}$} \\
\hline Processo & $\begin{array}{l}\text { 9) Produção local } \\
\text { Pode ser produzido localmente? }\end{array}$ & $\begin{array}{l}\text { 10) Controle e reparo local } \\
\text { Pode ser controlado, mantido } \\
\text { e reparado localmente? }\end{array}$ & $\begin{array}{l}\text { 11) Colaboração } \\
\text { Considera e engaja to- } \\
\text { dos os stakeholders? }\end{array}$ & \\
\hline \multirow[t]{4}{*}{ Produto } & $\begin{array}{l}\text { 1) Necessidade } \\
\text { O usuário ou comunidade precisam da } \\
\text { solução? Respeita a dignidade humana }\end{array}$ & $\begin{array}{l}\text { 5) Qualidade } \\
\text { É robusta e duradoura? Atende } \\
\text { aos requisitos e normas? }\end{array}$ & \multirow{2}{*}{$\begin{array}{l}\text { 12) Transparência } \\
\text { Há documentação de } \\
\text { suporte? A informação } \\
\text { é compartilhada? }\end{array}$} & \multirow{4}{*}{$\begin{array}{l}\text { 16) Sistemicidade } \\
\text { A solução é } \\
\text { isolada ou } \\
\text { desencadeia uma } \\
\text { mudança social } \\
\text { mais ampla? }\end{array}$} \\
\hline & $\begin{array}{l}\text { 2) Adequação } \\
\text { É social, cultural e ambientalmente } \\
\text { apropriada? }\end{array}$ & $\begin{array}{l}\text { 6) Ajustabilidade } \\
\text { É flexível e adaptativo às mudanças } \\
\text { do contexto? }\end{array}$ & & \\
\hline & $\begin{array}{l}\text { 3) Acesso } \\
\text { É acessível agora e no futuro? }\end{array}$ & $\begin{array}{l}\text { 7) Inclusividade } \\
\text { É inclusiva para grupos marginalizados ou } \\
\text { prioriza grupos específicos de usuários? }\end{array}$ & \multirow{2}{*}{$\begin{array}{l}\text { 13) Escalabilidade } \\
\text { O processo produtivo } \\
\text { é replicável e } \\
\text { escalável? }\end{array}$} & \\
\hline & $\begin{array}{l}\text { 4) Usabilidade } \\
\text { É compreensível e fácil de usar? }\end{array}$ & $\begin{array}{l}\text { 8) Complementaridade } \\
\text { Suporta soluções existentes e evita } \\
\text { redundâncias desnecessárias? }\end{array}$ & & \\
\hline
\end{tabular}

Figura 1 - Design for Social Sustainability Framework para projetos humanitários e de desenvolvimento

Fonte: CORSINI, MOULTRIE, 2019 


\section{RESULTADOS}

\subsection{Solução 01: Suportes para face shields (re- posição de peças)}

O autor deste projeto de pesquisa participou de um grupo colaborativo formado por cerca de 40 pessoas e empresas na cidade de Londrina/PR para a produção de equipamentos de proteção do tipo face shield para o HU/UEL. Este equipamento é composto de um suporte impresso em 3D (Figura 2), ao qual é fixada uma lâmina transparente e flexível de plástico tereftalato de polietileno (PET), que funciona como barreira microbiológica protegendo o profissional de saúde de eventuais contaminações ao atender pacientes infectados. A iniciativa foi realizada durante os meses de abril e maio de 2020, e cerca de duas mil máscaras foram entregues ao hospital universitário, das quais 120 foram produzidas pelo autor deste projeto. Esta iniciativa foi amplamente divulgada na mídia local.

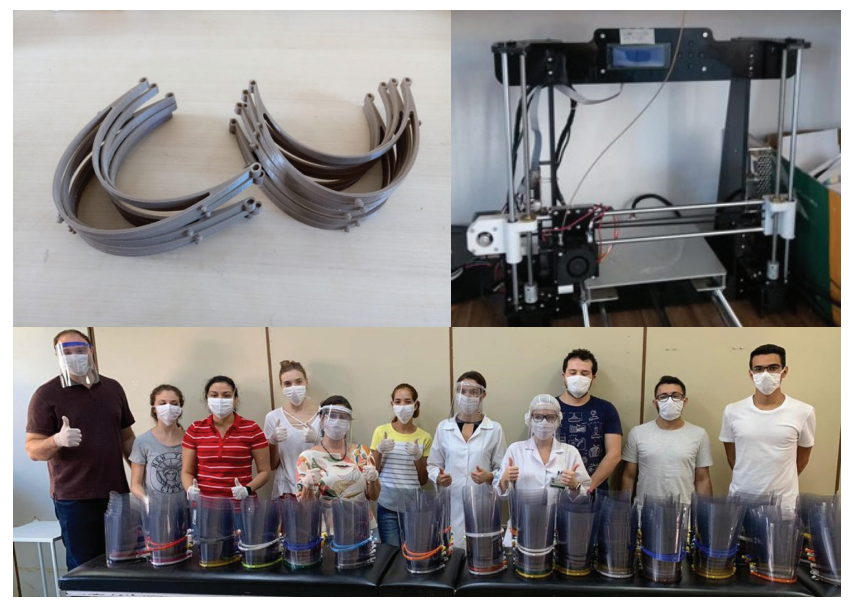

Figura 2: Suportes para face shields (a) produzidos utilizando impressão 3D FFM (b) e montados por equipe de colaboradores do hospital (c).

Fonte: Autores.

\subsubsection{Análise da solução 01 com base no DfSS} Framework

A fim de facilitar a visualização do nível de desempenho de sustentabilidade social para cada um dos aspectos de análise, utilizou-se uma codificação simples por meio de três cores: verde (aspectos contemplados de forma satisfatória na solução analisada), amarelo (aspectos que precisam ser melhorados e requerem maior atenção) e vermelho (aspectos críticos que precisam ser considerados e ainda não foram contemplados de forma satisfatória).

Considerando cada um dos níveis do DfSS framework (Figura 3), pode-se considerar que, em nível de produto, a solução 1 era necessária para a situação emergencial em que foi criada (1), mas sem preocupações maiores com as questões de adequação (2), usabilidade (4), qualidade (5), pois apresentava alguns problemas de desconforto no uso e falta de qualidade provocados pelas limitações do próprio processo produtivo. Algumas dificuldades de complementaridade (8) também puderam ser observadas, principalmente no que diz respeito a redundâncias desnecessárias, uma vez que foram identificadas soluções mais eficientes em termos de uso de materiais e do processo produtivo. Por exemplo, alguns pesquisadores já haviam desenvolvido face shields feitas de um único material (chapa PETG), sem a necessidade de impressão 3D dos suportes em poliácido láctico $(P L A)$, mas como o processo de produção já estava em andamento o grupo de colaboradores optou por seguir em frente com esta última solução. Ainda sobre o nível de produto, havia dificuldades no compartilhamento de informações técnicas sobre o processo de impressão (12), bem como limitações de escalabilidade (13) inerentes ao processo escolhido, que apesar de ser replicável e rapidamente ajustável, limitava a quantidade de peças produzidas diariamente pela rede de colaboradores. No que diz respeito ao processo, deve-se ressaltar os benefícios advindos da impressão feita na própria cidade (9) de forma aberta e colaborativa por meio de uma rede de colaboradores altamente engajados (11), e que possibilitou a manutenção, reparo e rápida substituição de componentes da face shield em nível local (10).

\begin{tabular}{|l|l|l|l|l|}
\hline Paradigma & \multicolumn{2}{|l|}{$\begin{array}{l}\text { 14) Avanço } \\
\text { Cria postos de trabalho no país? Aproveita as habilidades } \\
\text { existentes? Desenvolve novas habilidades? }\end{array}$} & \multicolumn{2}{l|}{$\begin{array}{l}\text { 15) Empoderamento } \\
\text { Reduz a dependência? Empodera pessoas } \\
\text { para desenvolver suas próprias soluções? }\end{array}$} \\
\hline Processo & $\begin{array}{l}\text { 9) Produção local } \\
\text { Pode ser produzido localmente? }\end{array}$ & $\begin{array}{l}\text { 10) Controle e reparo local } \\
\text { Pode ser controlado, mantido } \\
\text { e reparado localmente? }\end{array}$ & $\begin{array}{l}\text { 11) Colaboração } \\
\text { Considera e engaja to- } \\
\text { dos os stakeholders? }\end{array}$ & \\
\hline Produto & $\begin{array}{l}\text { 1) Necessidade } \\
\text { O usuário ou comunidade precisam da } \\
\text { solução? Respeita a dignidade humana }\end{array}$ & $\begin{array}{l}\text { 5) Qualidade } \\
\text { É robusta e duradoura? Atende } \\
\text { aos requisitos e normas? }\end{array}$ & $\begin{array}{l}\text { 12) Transparência } \\
\text { Há documentação de } \\
\text { suporte? A informação } \\
\text { é compartilhada? }\end{array}$ & $\begin{array}{l}\text { A solução é isolada } \\
\text { ou desencadeia } \\
\text { uma mudaça } \\
\text { social mais ampla? }\end{array}$ \\
\hline
\end{tabular}




\begin{tabular}{|l|l|l|l|l|}
\hline $\begin{array}{l}\text { Produto } \\
\text { (continu- } \\
\text { ação) }\end{array}$ & $\begin{array}{l}\text { 2) Adequação } \\
\text { É social, cultural e ambientalmente } \\
\text { apropriada? }\end{array}$ & $\begin{array}{l}\text { 6) Ajustabilidade } \\
\text { É flexível e adaptativo às mudanças } \\
\text { do contexto? }\end{array}$ & $\begin{array}{l}\text { 12) Transparência } \\
\text { Há documentação de } \\
\text { suporte? A informação } \\
\text { é compartilhada? }\end{array}$ & $\begin{array}{l}\text { 16) Sistemicidade } \\
\text { A solução é isolada } \\
\text { ou desencadeia } \\
\text { uma mudança } \\
\text { social mais ampla? }\end{array}$ \\
\cline { 2 - 4 } & $\begin{array}{l}\text { 3) Acesso } \\
\text { É acessível agora e no futuro? }\end{array}$ & $\begin{array}{l}\text { 7) Inclusividade } \\
\text { É inclusiva para grupos marginalizados ou } \\
\text { prioriza grupos específicos de usuários? }\end{array}$ & $\begin{array}{l}\text { 13) Escalabilidade } \\
\text { O processo produtivo } \\
\text { é replicável e } \\
\text { escalável? }\end{array}$ & $\begin{array}{l}\text { 8) Complementaridade } \\
\text { Suporta soluções existentes e evita } \\
\text { redundâncias desnecessárias? }\end{array}$ \\
\cline { 2 - 5 } & $\begin{array}{l}\text { 4) Usabilidade } \\
\text { É compreensível e fácil de usar? }\end{array}$ & & \\
\hline
\end{tabular}

Figura 3 - Avaliação retrospectiva da solução 1 por meio do DfSS Framework Fonte: CORSINI, MOULTRIE, 2019).

No nível de paradigma, pode-se considerar com parcialmente positivo o empoderamento da comunidade de colaboradores (15) em utilizar uma tecnologia aberta de impressão 3D, seja nos equipamentos de impressão, nos softwares de código aberto ou mesmo no uso de modelos abertos disponibilizados pela comunidade aberta internacional, reduzindo a dependência de fornecedores externos, ainda que de forma temporária. No entanto, não se trata de uma solução que chega a transformar o contexto econômico, criando novos negócios e postos de trabalho (15), embora tenha utilizado habilidades existentes na comunidade maker da cidade, e até mesmo ajudado a desenvolver algumas novas habilidades, incluindo a articulação rápida e orgânica (a rede cresceu em tamanho a cada semana) da própria rede. Também parece precoce afirmar que tal ação desencadeia uma mudança social e sistêmica mais ampla (16), mas a rápida reação da rede de colaboradores indicou que havia já um potencial colaborativo e técnico latente pronto para ser utilizado, e que quando foi acionado respondeu de forma apropriada. Tal fato pode apontar indícios de uma mudança social maior caso este potencial seja bem aproveitado e incentivado no futuro.

\subsection{Solução 02: Conector para sistema fechado de aspiração de fluidos}

Esta solução foi desenvolvida graças a uma parceria entre os autores, ambos docentes da UEL, do departamento de Design e Fisioterapia, a fim de solucionar o problema da falta de acesso a equipamento adequado para aspiração de fluidos (secreção pulmonar), sem expor a via aérea de pacientes infectados com consequente disseminação do vírus no ambiente.

A escassez, a alta procura no cenário mundial e o aumento substancial de preço de um equipamento de aspiração fechada foram os motivadores para se buscar uma solução que pudesse ser desenvolvida e produzida localmente. A solução foi desenvolvida no período de abril a junho de 2020 utilizando-se um processo de caráter altamente experimental com base em design com tecnologias de modelagem 3D digital (Figura 4a) e impressão 3D (Figura 4b), e encontra-se atualmente em fase final de validação junto ao HU/UEL com realização de testes de uso (Figura 4c), devendo ser divulgada e implantada em breve.

Estimativas preliminares apontaram uma redução significativa de custo para o equipamento produzido localmente, ficando em torno de $35 \%$ do preço de venda do equipamento importado. A adoção emergencial destas duas soluções por parte do HU reforça a viabilidade técnica e econômica da fabricação digital para o uso em hospitais públicos e, portanto, a relevância e potencial de implementação do projeto aqui proposto.

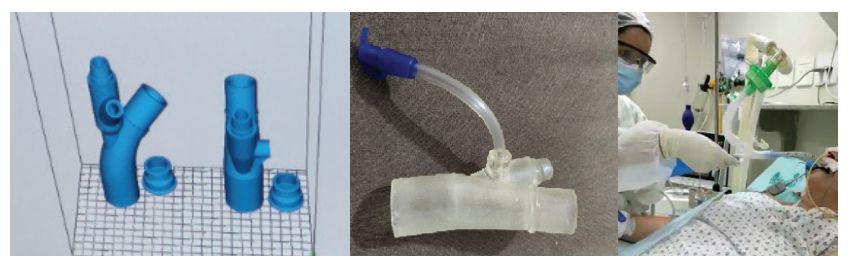

Figura 4 (a), (b) e (c) - Protótipo do conector.

Fonte: Autores.

\subsubsection{Análise da solução 02 com base no DfSS Framework}

Considerando-se o DfSS (Figura 5), a solução 2 apresenta no nível do produto aspectos positivos, pois trata-se de um equipamento: extremamente necessário e adequado para o atendimento dos pacientes e proteção dos profissionais de saúde $(1,2)$; acessível desde que seja feita a aquisição do equipamento e insumos necessários e treinamento do pessoal para o desenvolvimento e produção (3); com uma usabilidade e qualidade ligeiramente inferior ao equipamento de mercado, mas suficiente para a tarefa (4); flexível e adaptável em termos de design devido ao próprio processo de desenvolvimento e produção adotado, em pequena escala (6); inclusivo, ao possibilitar adaptações de design para grupos específicos, como crianças ou idosos (7); que aproveita de forma complementar componentes disponíveis no 
mercado nacional combinando-os com a impressão 3D (8); replicável devido ao processo utilizado (13), embora com algumas limitações de escala inerentes à tecnologia, mas que se mostra adequado à necessidade de pequenos lotes por parte do hospital. A transparência da informação é ainda um aspecto a ser melhorado, com a elaboração de documentação técnica adequada (12).

No nível do processo, foram identificadas vantagens significativas quanto à possibilidade de produção local e próxima ao hospital (9), bem como o controle e reparo (10), embora a colaboração (11), principalmente na prototipagem e produção, não seja um aspecto tão relevante como no caso da solução 1 (face shields) devido ao processo de impressão adotado, Digital Light Processing (DLP), que limita a quantidade de colaboradores que tenham esse tipo de equipamento; mesmo assim foi possível contar com a ajuda de um profissional de odontologia, externo ao hospital, que tinha o equipamento adequado.

\begin{tabular}{|c|c|c|c|c|}
\hline \multirow{2}{*}{$\begin{array}{l}\text { Paradigma } \\
\text { Processo }\end{array}$} & \multicolumn{2}{|c|}{$\begin{array}{l}\text { 14) Avanço } \\
\text { Cria postos de trabalho no país? Aproveita as habilidades } \\
\text { existentes? Desenvolve novas habilidades? }\end{array}$} & \multicolumn{2}{|c|}{$\begin{array}{l}\text { 15) Empoderamento } \\
\text { Reduz a dependência? Empodera pessoas } \\
\text { para desenvolver suas próprias soluções? }\end{array}$} \\
\hline & $\begin{array}{l}\text { 9) Produção local } \\
\text { Pode ser produzido localmente? }\end{array}$ & $\begin{array}{l}\text { 10) Controle e reparo local } \\
\text { Pode ser controlado, mantido } \\
\text { e reparado localmente? }\end{array}$ & $\begin{array}{l}\text { 11) Colaboração } \\
\text { Considera e engaja to- } \\
\text { dos os stakeholders? }\end{array}$ & \\
\hline Produto & $\begin{array}{l}\text { 1) Necessidade } \\
\text { O usuário ou comunidade precisam da } \\
\text { solução? Respeita a dignidade humana }\end{array}$ & $\begin{array}{l}\text { 5) Qualidade } \\
\text { É robusta e duradoura? Atende } \\
\text { aos requisitos e normas? }\end{array}$ & $\begin{array}{l}\text { 12) Transparência } \\
\text { Há documentação de } \\
\text { suporte? A informação } \\
\text { é compartilhada? }\end{array}$ & $\begin{array}{l}\text { 16) Sistemicidade } \\
\text { A solução é isolada } \\
\text { ou desencadeia } \\
\text { uma mudança } \\
\text { social mais ampla? }\end{array}$ \\
\hline \multirow[t]{3}{*}{$\begin{array}{l}\text { Produto } \\
\text { (continu- } \\
\text { ação) }\end{array}$} & $\begin{array}{l}\text { 2) Adequação } \\
\text { É social, cultural e ambientalmente } \\
\text { apropriada? }\end{array}$ & $\begin{array}{l}\text { 6) Ajustabilidade } \\
\text { É flexível e adaptativo às mudanças } \\
\text { do contexto? }\end{array}$ & & \\
\hline & $\begin{array}{l}\text { 3) Acesso } \\
\text { É acessível agora e no futuro? }\end{array}$ & $\begin{array}{l}\text { 7) Inclusividade } \\
\text { É inclusiva para grupos marginalizados ou } \\
\text { prioriza grupos específicos de usuários? }\end{array}$ & \multirow{2}{*}{$\begin{array}{l}\text { 13) Escalabilidade } \\
\text { O processo produtivo } \\
\text { é replicável e } \\
\text { escalável? }\end{array}$} & \\
\hline & $\begin{array}{l}\text { 4) Usabilidade } \\
\text { É compreensível e fácil de usar? }\end{array}$ & $\begin{array}{l}\text { 8) Complementaridade } \\
\text { Suporta soluções existentes e evita } \\
\text { redundâncias desnecessárias? }\end{array}$ & & \\
\hline
\end{tabular}

Figura 5 - Avaliação retrospectiva da solução 2 por meio do DfSS Framework

Fonte: CORSINI, MOULTRIE, 2019).

No nível de paradigma ainda não há condições de responder se a solução promove avanço efetivo na criação de oportunidades de trabalho (14), embora o projeto tenha se beneficiado de habilidades técnicas existentes (e até mesmo desenvolvido algumas novas), tanto de pesquisadores quanto de parceiros privados, pois o consultório odontológico parceiro do projeto já utiliza a impressora DLP em seu processo de trabalho. A redução da dependência de fornecedores externos é um dos pontos altos esperados com a implementação da solução (15), embora a autonomia de desenvolvimento pelos stakeholders seja ainda limitada pela falta de um sistema de capacitação adequado à solução desenvolvida. Em termos sistêmicos (16), não se pode ainda afirmar que a solução provoca ou não uma mudança social maior, por exemplo em termos de maior acesso pela população, embora esta seja uma das expectativas dos pesquisadores ao se implementar esta solução no hospital.

\subsection{Solução 03: Núcleo de fabricação digital e inovação do HU/UEL}

\subsubsection{Descrição da solução 03}

A partir da experiência obtida no desenvolvimento dos projetos anteriormente mencionados, da crise provocada pela pandemia de COVID-19 e da possibilidade de que este tipo de crise se torne cada vez mais frequente, vislumbramos a necessidade e a possibilidade de criar e implementar um núcleo permanente de fabricação digital e inovação junto ao Hospital Universitário de Londrina (Figura 6 e 7). Este núcleo tem caráter interdisciplinar, e seu objetivo é pesquisar, desenvolver, produzir e fornecer, soluções e equipamentos hospitalares personalizados, para os profissionais da saúde e para os diversos setores do hospital, em quantidade suficiente e no tempo correto, a fim de ampliar a efetividade e eficiência dos serviços prestados pelo hospital, enquanto reduz sua dependência de fornecimento externo de equipamentos diversos. 
O sistema é composto pelo laboratório, a articulação em rede com a comunidade maker e os cursos de graduação e pós-graduação da Universidade Estadual de Londrina (UEL). O laboratório já se encontra em fase de montagem (Figura 8a e 8b).

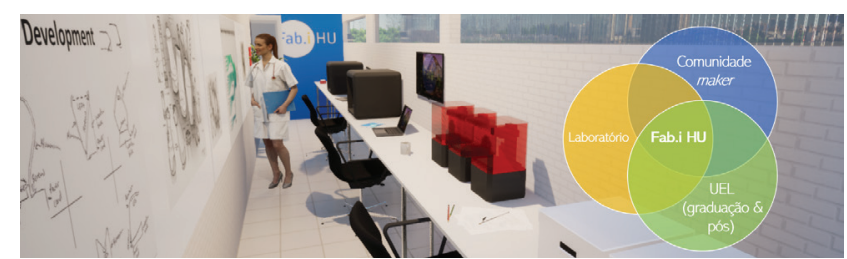

Figura 6 - Projeto do laboratório do núcleo de fabricação digital e inovação do HU (Fab.i HU), a ser inaugurado em agosto de 2021, um dos elementos do sistema Fab.i HU. Fonte: Autores.

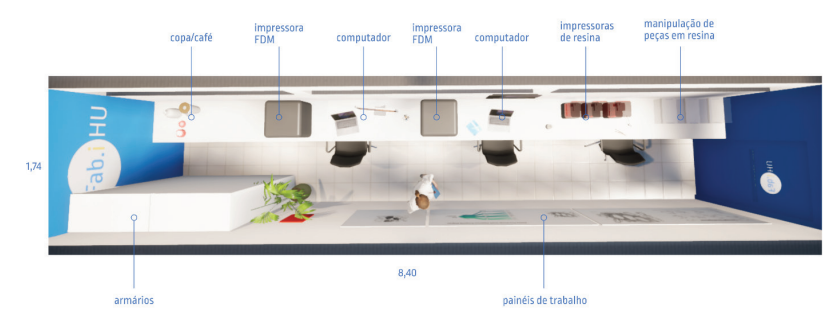

Figura 7 - Layout do novo Fab.i HU. Fonte: Autores.



Figura 8 (a) e (b) - Instalação do laboratório do novo Fab.i HU. Fonte: Autores.

\subsubsection{Análise d2 a solução 03 com base no DfSS Framework}

A solução 3 apresenta características distintas das soluções 1 e 2, pois enquanto as duas primeiras referem-se a produtos ela se baseia em um sistema, o qual inclui produtos, processos, serviços e uma estratégia de organização e operação. Além disso, enquanto os produtos analisados já foram ou estão em desenvolvimento, a solução 3 encontra-se ainda em fase de implementação, e portanto só pode ser avaliada de forma prospectiva. Feita esta observação, pode-se considerar que os requisitos de sustentabilidade social do framework DfSS (Figura 9) deverão funcionar como diretrizes, tanto projetuais quanto de avaliação, para o desenvolvimento de qualquer produto ou processo que venha a ser desenvolvido no núcleo de fabricação digital. A avaliação destes requisitos foi feita, neste caso, considerando-se as potenciais dificuldades de atendimento para cada um deles.

No nível de produto, deve-se considerar que: o núcleo de fabricação digital deverá desenvolver produtos para diversas necessidades do hospital (1), dependendo da demanda e urgência, e que sejam apropriadas ao contexto da instituição (2), acessíveis para ela e para o público-alvo (3), e com usabilidade (4), qualidade (5), ajustabilidade (6), inclusividade (7) e complementaridade (8) adequadas. Destes, e com base no aprendizado obtido nas experiências com produtos (Soluções 1 e 2), pode-se inferir que poderão ser encontradas maiores dificuldades nas questões de usabilidade (4) e qualidade (5), principalmente ao se desenvolver e produzir produtos com maior complexidade, e devido a limitações tecnológicas próprias dos processos de impressão 3D. A transparência (12) por meio de documentação adequada, aberta e compartilhada, representa outro desafio para o sucesso do sistema, assim como a escalabilidade (13), que deve ser prevista com atenção para cada tipo de solução demandada pelo hospital.

No nível de processo, a possibilidade de produção (9), controle e reparo local (10) são relativamente fáceis de se atender pelas próprias características intrínsecas à fabricação digital; a colaboração (11), no entanto, apresenta um nível maior de dificuldade de implementação, pois exige uma capacidade de articulação de atores que precisa ser construída cuidadosamente.

Finalmente, no nível de paradigma deve-se considerar com atenção alternativas que permitam ao sistema criar novas fontes de trabalho e renda (14), seja no próprio sistema ou a partir de novos negócios que possam ser criados ou aprimorados a partir dele. Tanto a identificação das habilidades já existentes no sistema quanto a criação de novas devem ser consideradas, uma vez que se trata de um tipo de sistema que requer um alto nível de conhecimento técnico e científico. 


\begin{tabular}{|c|c|c|c|c|}
\hline \multirow{2}{*}{$\begin{array}{l}\text { Paradigma } \\
\text { Processo }\end{array}$} & \multicolumn{2}{|c|}{$\begin{array}{l}\text { 14) Avanço } \\
\text { Cria postos de trabalho no país? Aproveita as habilidades } \\
\text { existentes? Desenvolve novas habilidades? }\end{array}$} & \multicolumn{2}{|c|}{$\begin{array}{l}\text { 15) Empoderamento } \\
\text { Reduz a dependência? Empodera pessoas } \\
\text { para desenvolver suas próprias soluções? }\end{array}$} \\
\hline & $\begin{array}{l}\text { 9) Produção local } \\
\text { Pode ser produzido localmente? }\end{array}$ & $\begin{array}{l}\text { 10) Controle e reparo local } \\
\text { Pode ser controlado, mantido } \\
\text { e reparado localmente? }\end{array}$ & $\begin{array}{l}\text { 11) Colaboração } \\
\text { Considera e engaja to- } \\
\text { dos os stakeholders? }\end{array}$ & \\
\hline Produto & $\begin{array}{l}\text { 1) Necessidade } \\
\text { O usuário ou comunidade precisam da } \\
\text { solução? Respeita a dignidade humana }\end{array}$ & $\begin{array}{l}\text { 5) Qualidade } \\
\text { É robusta e duradoura? Atende } \\
\text { aos requisitos e normas? }\end{array}$ & $\begin{array}{l}\text { 12) Transparência } \\
\text { Há documentação de } \\
\text { suporte? A informação } \\
\text { é compartilhada? }\end{array}$ & $\begin{array}{l}\text { 16) Sistemicidade } \\
\text { A solução é isolada } \\
\text { ou desencadeia } \\
\text { uma mudança } \\
\text { social mais ampla? }\end{array}$ \\
\hline \multirow[t]{3}{*}{$\begin{array}{l}\text { Produto } \\
\text { (continu- } \\
\text { ação) }\end{array}$} & $\begin{array}{l}\text { 2) Adequação } \\
\text { É social, cultural e ambientalmente } \\
\text { apropriada? }\end{array}$ & $\begin{array}{l}\text { 6) Ajustabilidade } \\
\text { É flexível e adaptativo às mudanças } \\
\text { do contexto? }\end{array}$ & & \\
\hline & $\begin{array}{l}\text { 3) Acesso } \\
\text { É acessível agora e no futuro? }\end{array}$ & $\begin{array}{l}\text { 7) Inclusividade } \\
\text { É inclusiva para grupos marginalizados ou } \\
\text { prioriza grupos específicos de usuários? }\end{array}$ & \multirow{2}{*}{$\begin{array}{l}\text { 13) Escalabilidade } \\
\text { O processo produtivo } \\
\text { é replicável e } \\
\text { escalável? }\end{array}$} & \\
\hline & $\begin{array}{l}\text { 4) Usabilidade } \\
\text { É compreensível e fácil de usar? }\end{array}$ & $\begin{array}{l}\text { 8) Complementaridade } \\
\text { Suporta soluções existentes e evita } \\
\text { redundâncias desnecessárias? }\end{array}$ & & \\
\hline
\end{tabular}

Figura 9 - Avaliação prospectiva da solução 3 por meio do DfSS framework

Fonte: CORSINI, MOULTRIE, 2019

A capacitação dos diversos atores do sistema é outro aspecto que merece atenção, a fim de criar maior autonomia e capacidade de ação (15), reduzindo a necessidade de dependência externa. Uma vez que estes critérios de sustentabilidade social sejam considerados com profundidade no sistema, e buscando-se uma articulação mais ampla com outras redes de colaboração semelhantes em nível local, regional e nacional, a chance de se promover uma mudança social mais ampla, evitando assim que o sistema seja apenas uma solução isolada. Tal sistemicidade representa, portanto, um desafio significativo a ser enfrentado no desenvolvimento do sistema.

Para uma implementação efetiva deste tipo de espaço, Pietila (2021) propõe que sejam observados alguns aspectos importantes, como: considerar qual é a escala do sistema, se departamental ou institucional; caso utilize imagem digital 3d, considerar o formato mais adequado e viável (CT, MRI ou ultrassom 3D); considerar as necessidades de software mais adequadas ao fluxo de trabalho; como ampliar a colaboração e o fluxo de informações (ex. modelos digitais 3D) a fim de facilitar a comunicação entre a equipe do laboratório e o restante do hospital; definir se o laboratório será interno ao hospital ou terceirizado, pois cada uma destas modalidades tem seus pontos fortes e fracos que deve ser considerado conforme a necessidade e recursos do hospital; caso seja interno, quais são as necessidades de treinamento especíico para que o laboratório possa ser operado. A fim de criar condições para que o sistema tenha sucesso caso seja implementado internamente, Pietila (idem) recomenda que se inicie em pequena escala enquanto se busca aprender rapidamente e ampliar o apoio dos demais profissionais do hospital para o sistema.

\section{DISCUSSÃO}

O instrumento DfSS framework permitiu avaliar de forma clara e objetiva, ainda que qualitativa, o tripé produto, processo e paradigma, a fim de que seja possível criar soluções com foco não só no usuário, mas também no sistema. $\mathrm{O}$ DfSS permite ampliar o todo, baseado no design, na fabricação, no uso e na manutenção, entre outros, com consequente expansão do impacto social (CORSINI E MOULTRIE, 2019). Esses autores afirmam ser este um instrumento capaz de fornecer diretrizes para o planejamento e avaliação de projetos. $O$ presente instrumento vem de encontro às necessidades da solução 1, 2 e 3 expostas neste artigo, pois possibilita uma visão clara, ampla e transparente das etapas de planejamento e avaliação do processo do projeto. O quadro possibilitou uma análise mais profunda do impacto das intervenções, auxiliando na identificação de fatores que podem ser negligenciados durante o andamento do projeto, o que pode minimizar os erros.

Em relação ao nível de sustentabilidade das três soluções apresentadas, foi possível observar que as duas primeiras, embora sendo produtos, apresentaram características diferentes; o fato da primeira solução (suporte para face shield) ser baseada em um modelo aberto disponibilizado pela comunidade aberta para impressão e eventuais alterações implicou em algumas limitações de adequação, usabilidade, qualidade e complementaridade, as 
quais foram menos críticas na segunda solução (conector para sistema fechado), embora esta última ainda se encontre em desenvolvimento.

Tal comparação evidencia também as possibilidades e limitações dos processos de impressão 3D por deposição, no caso da solução 1, e DLP, na solução 2, notadamente em termos de escalabilidade e envolvimento dos stakeholders. Ambas oferecem oportunidades de avanço econômico e social, mas este é um aspecto ainda a ser explorado, e um dos motivos pelos quais foi desenvolvida a solução 3 (núcleo de fabricação digital). Este núcleo foi pensado como uma resposta para melhor atender às questões em nível de processo e paradigma, ao mesmo tempo em que explora os aprendizados obtidos com as experiências em nível de produto anteriores. Além disso, a proposta sistêmica do núcleo foi reconhecida como relevante pela agência oficial de fomento do Estado do Paraná (Fundação Araucária), que concedeu à equipe idealizadora do Fab.i HU fomento para compra de equipamentos e insumos que viabilizarão a implementação deste sistema, cujo laboratório já está sendo montado e com inauguração prevista para o mês de agosto de 2021.

\section{REFERÊNCIAS}

BROWN, T. Design Thinking: Uma metodologia poderosa para decretar o fim das velhas ideias. Rio de Janeiro: Alta Books, 2010.

CRAVEN, M.; LIU, L.; MYSORE, M.; WILSON, M. COVID-19: Implications for business. McKinsey \& Company. Disponível em: https:// www.mckinsey.com/business-functions/risk/our-insights/ COVID-19-implicationsfor-business. Acesso em: 8 fev. 2021.

CHOONG, Y.Y.C. et al. The global rise of 3D printing during the COVID-19 pandemic. Nature Reviews Materials. V. 5, p. 637-639, 2020.

CORSINI, L.; DAMMICCO, V.; MOULTRIE, J. Frugal innovation in a crisis: the digital fabrication maker response to COVID-19. R\&D Management, Cambridge, v. 51, n. 2, p. 195-210, 2021.

CORSINI, L.; MOULTRIE, J. Design for social sustainability: Using digital fabrication in the humanitarian and development sector. Sustainability, Suíça, v. 11, n. 13, 2019.

DA COSTA JUNIOR, J.; DIEHL, J. C.; SNELDERS, D. A framework for a systems design approach to complex societal problems. Design Science, v.5 e.2, Cambridge University Press, 2019.

ELLEN MCARTHUR FOUNDATION. Disponível em <https://www.ellenmacarthurfoundation.org/> Acesso em: 12 jan 2020.

GERSHENFELD, N. How to Make Almost Anything: The Digital Fabrication Revolution. Foreign Affairs, v. 91, n. 6 , p. 43-57, 2012. Disponível em: http://access.library.unisa.edu.au/login?url=http://search.proquest. com/docview/1223498609? accountid=14649\%5Cnhttp://www.library.unisa.edu.au/applications/findit/ ?ctx_ver=Z39.88-2004\&ctx_enc=info:ofi/enc:UTF-8\&rfr_id=info:sid/ProQ\%3Aabiglobal\&rft_val_fmt. Acesso em: 08 jun 2020.

ISON, R. Systems Practice: How to Act in a ClimateChange World. Londres: Springer, 2010.

MANZINI, E.; VEZZOLI, Carlo. O Desenvolvimento de Produtos Sustentáveis: os requisitos ambientais dos produtos industriais. São Paulo: Edusp - Editora da Universidade de São Paulo, 2002.

PIETILA, T. 6 Considerations for Implementing a 3D Printing Core Service in Your Hospital. Medical 3D Printing Webinar series. Materialise. Disponível em https://www.materialise.com/en/resources/medical/ whitepapers/6-considerations-for-implementing-a-3d-printing-core-service-your-hospital Acesso 11 jun 2021.

RITTEL, H.W.J.; WEBBER, M.M. Dilemmas in a general theory of planning. Policy Sci, n. 4, p. 155-169, 1973. Disponível em: https://doi.org/10.1007/BF01405730. Acesso em: 14 mar 2019.

SNOWDEN, D. J. Multi-ontology sense making: A new simplicity in decision making. Informatics in Primary Care, v. 13, n. 1, p. 45-53, 2005.

VANDENBROECK, P. Systems thinking and four forms of complexity. Antuérpia: Shiftn, 2015.

VEZZOLI, Carlo. Design de sistemas para sustentabilidade: teoria, métodos e ferramentas para o design sustentável de "sistemas de satisfação". Salvador: EDUFBA, 2010.

VOLPATO, Neri. Prototipagem Rápida: tecnologias e aplicações. São Paulo: Editora Blücher, 2007. 


\section{AUTORES}

ORCID https://orcid.org/0000-0003-2310-8674

CLAUDIO PEREIRA DE SAMPAIO, Dr. | Universidade Estadual de Londrina (UEL), Departamento de Design, Londrina/PR/ Brasil | Endereço: Rua Rodolfo Preto, 230 Jardim Columbia D, CEP 86057382. Email: claudiopereira@uel.br

ORCID 0000-0003-4785-6765

SONIA MARIA FABRIS LUIZ, Dra. | Universidade Estadual de Londrina (UEL), Departamento de Fisioterapia, Londrina/ PR/Brasil. Endereço: . Email: sofabrisuel.br | Rua Dr Elias César, 220, apto 304. Caiçaras. 86015640

\section{COMO CITAR ESTE ARTIGO}

SAMPAIO, Claudio Pereira de; LUIZ, Sônia Maria Fabris. Design E Impressão 3D Na Pandemia: Uma Análise De Possibilidades A Partir Do Modelo Teórico DFSS. MIX Sustentável, [S.I.], v. 7, n. 4, p. 149-160, set. 2021. ISSN 24473073. Disponível em:<http://www.nexos. ufsc.br/index.php/mixsustentavel>. Acesso em: dia mês. ano. doi:https://doi.org/10.29183/2447-3073. MIX2021.v7.n4.149-160. 
